\title{
A Bilevel Mathematical Approach for the Empty Container Repositioning Proble with a Sharing and Exchanging Strategy in Liner Shipping
}

\author{
Dung-Ying Lin \\ Department of Industrial Engineering and Engineering Management, National Tsing Hua University, Hsinchu City, \\ Taiwan
}

Chieh-Ju Juan

Department of Aviation Management, Republic of China Air Force Academy, Kaohsiung City, Taiwan, r58061021@gs.ncku.edu.tw

Follow this and additional works at: https://jmstt.ntou.edu.tw/journal

Part of the Fresh Water Studies Commons, Marine Biology Commons, Ocean Engineering Commons, Oceanography Commons, and the Other Oceanography and Atmospheric Sciences and Meteorology Commons

\section{Recommended Citation}

Lin, Dung-Ying and Juan, Chieh-Ju (2021) "A Bilevel Mathematical Approach for the Empty Container Repositioning Proble with a Sharing and Exchanging Strategy in Liner Shipping," Journal of Marine Science and Technology: Vol. 29: Iss. 3, Article 13.

DOI: 10.51400/2709-6998.1444

Available at: https://jmstt.ntou.edu.tw/journal/vol29/iss3/13

This Research Article is brought to you for free and open access by Journal of Marine Science and Technology. It has been accepted for inclusion in Journal of Marine Science and Technology by an authorized editor of Journal of Marine Science and Technology. 


\title{
A Bilevel Mathematical Approach for the Empty Container Repositioning Problem with a Sharing and Exchanging Strategy in Liner Shipping
}

\author{
Dung-Ying Lin ${ }^{a}$, Chieh-Ju Juan ${ }^{\mathrm{b}, *}$ \\ a Department of Industrial Engineering and Engineering Management, National Tsing Hua University, Hsinchu City, 30013, Taiwan \\ ${ }^{\mathrm{b}}$ Department of Aviation Management, Republic of China Air Force Academy, Kaohsiung City, 82047, Taiwan
}

\begin{abstract}
In the maritime industry, the management of empty containers is a significant issue whose costs account for a large proportion of the total world fleet running costs. To reduce repositioning activities and increase cost effectiveness, this paper proposes a solution framework considering empty container sharing and exchanging strategies to coordinate the shipping lines in a maritime transportation network. The proposed solution framework considers an empty container matching platform company and a group of shipping lines in a given shipping network. Because of the interactive relationship between the two parties, the proposed problem is formulated as a bilevel programming problem, and the Karush-Kuhn-Tucker (KKT) is applied. To validate the proposed solution approach, a practical Asia-Europe-Oceania shipping network is used to conduct numerical experiments. The benefits of the proposed solution framework are shown in the results.
\end{abstract}

Keywords: Empty container repositioning, Liner shipping, Bilevel programming, Karush-Kuhn-Tucker conditions

\section{Introduction}

$\mathrm{T}$ he empty container repositioning problem is a significant challenge in the maritime industry because the container repositioning costs account for $27 \%$ of the total world fleet running costs [20]. Furthermore, as the maritime market rapidly develops, the costs of empty container repositioning increase simultaneously. From 1990 to 2010 , the traffic of empty containers increased by $657 \%$ (from 17.8 million TEUs to 116.9 million TEUs) while the world traffic increased by $624 \%$ (from 87.9 million TEUs to 548.5 million TEUs) [26]. The main cause of the empty container repositioning issue is the imbalance of imports and exports in world trade. However, because of the inevitable nature of the issue, the practical solution is mainly to adopt proper strategies to minimize the needed repositioning activities for satisfying traffic demand and thus reduce the costs for shipping lines.

To deal with the critical issue in the maritime industry, this paper proposes a bilevel solution framework considering empty container sharing and exchanging strategies to coordinate the shipping lines in a maritime transportation network and thus reduce the repositioning activities and improve the cost effectiveness. In the proposed solution framework, an empty container matching platform company and a group of shipping lines are considered to address the empty container repositioning problem in a cooperative manner. The core ideal is inspired by a company $\mathrm{N}$ who provides a platform to facilitate swaps of leased containers among

Received 4 November 2020; revised 14 December 2020; accepted 2 February 2021.

Available online 25 June 2021.

* Corresponding author.

E-mail address: r58061021@gs.ncku.edu.tw (C.-J. Juan). 
shipping lines. This paper extends this idea by considering an empty container matching platform company who provides a service that matches empty containers for a group of shipping lines and determines the exchange costs for different deficit ports to achieve a win-win situation where the matching platform company can maximize its profits and the shipping lines can satisfy their demands with the minimum costs. Based on the proposed solution structure, there is a pricing problem where a matching platform company aims to determine the proper exchange costs at different ports to maximize profits and the repositioning plans of empty containers made by shipping lines to maximize the cost effectiveness.

In the general traffic assignment problem, the different prices (i.e., costs) for roads affect the behaviors of the users in the network. Similarly, shipping lines change their empty container repositioning plans according to the exchange costs determined by the matching platform company that forms the interactive relationship between the two parties. Therefore, the proposed problem is formulated as a bilevel programming problem, and a Karush-Kuhn-Tucker (KKT)-based approach is applied to solve the problem. In the numerical experiments, a practical Asia-Europe-Oceania shipping network that consists of 46 major ports in Asia and Europe is applied to validate the proposed solution framework for empty container repositioning. The results show the benefits of adopting the sharing and exchanging strategies in repositioning plans. Moreover, the results of the exchange costs at different deficit ports are discussed. This research can provide a new idea and helpful insights regarding the empty container repositioning issue for shipping lines in the competitive shipping market.

\section{Literature review}

Since the issue of empty container repositioning is significant in the maritime industry, there have been a great number of papers related to this topic. Kuzmicz and Pesch [12] analyzed a variety of models and solution approaches for empty container repositioning problems, and they classified the approaches for empty container repositioning problems into technical and optimization methods.

In the optimization methods, mixed integer and continuous models constructed for the empty container repositioning problem were solved by exact algorithms or heuristic approaches. Furthermore, a variety of forms of models were developed, e.g., assignment, flow, location, routing, and inventory control models, but the main tendency was the network flow models that captured the nature of empty container repositioning [12].

Crainic et al. [5] studied the problem of allocating empty containers in a land distribution and transportation system. This paper was one of the first studies regarding the repositioning issue and was often quoted in the literature. In the paper, two dynamic deterministic formulations for the single and multicommodity cases were respectively introduced based on practical experience. Moreover, the various modeling issues related to this problem were comprehensively explored in the developed formulations. Shintani et al. [19] provided a simplified version of the network design problem where full and empty containers were both considered. The problem was formulated as a knapsack problem, and a genetic algorithm-based heuristic was developed to find the best port calling sequence that could maximize the profits of shipping lines. Long et al. [14] developed a time space network model for the empty container repositioning problem with an operational level that aimed to minimize the total empty container repositioning costs. Moreover, a rolling horizon method was applied to handle uncertainties in the forecasting data related to the supply, demand and available ship capacity. The results showed that the handling costs were the most sensitive parameter to the total costs. Brouer et al. [3] studied a cargo allocation problem considering the repositioning of empty containers for a shipping line company in which the aim was to maximize the profits of transported cargo subject to the costs and availability of empty containers. The problem was formulated as a multicommodity flow problem, and a column generation algorithm was applied to solve the problem.

Moreover, technical approaches solve the empty container repositioning problem by implementing foldable containers and connectainers. Zhang et al. [32] studied the empty container repositioning problem using foldable containers and considered the bridge height and water depth constraints in river-sea intermodal transport. A mathematical model was constructed to solve the problem, and the objective was to minimize the total costs. In the numerical experiments, the near-practical instances on the Yangtze River in China were used to illustrate the effectiveness and efficiency of foldable containers in container repositioning. There are other literatures that applied foldable containers to the empty container repositioning problem, and interested readers are referred to the following papers $[13,17,18,28,33,35]$. 
Moreover, according to the classifications proposed by Kuzmicz and Pesch [12], several strategies are commonly used for the empty container repositioning problem, e.g., container substitution, container sharing, and street turn strategies. Among these strategies, the container sharing strategy is recommended by several literatures to address the empty container repositioning issue. In $\mathrm{Xu}$ and Beamon [30], a coordination mechanism was used to manage the interdependence between organizations to improve the supply chain performance, and resource sharing was one of the attributes in the coordination mechanism. Furtado and Frayret [8] stated that the concept of resource sharing was a part of collaborative logistics that could improve the cost effectiveness and maintain the balance for companies owning containers in a market. In the maritime industry, container sharing is a strategy requiring horizontal cooperation between shipping lines that results in benefits, such as reduced costs, improved productivity and strengthened market positions [6]. Theofanis and Boile [24] examined empty container logistics at four different levels and stated that shipping lines could share their empty containers to match the demands of other shipping lines.

Some scholars developed a mathematical model to investigate the coordination mechanism in empty container repositioning. Song and Carter [21] proposed mathematical programming formulations to evaluate four strategies depending on whether there was coordination between shipping lines in the container flows and whether the sharing strategy was adopted by them for the empty container repositioning problem. The numerical results showed that the route coordination strategy was better than the container sharing strategy at decreasing empty container repositioning activities. $\mathrm{Xu}$ et al. [31] studied a sea cargo service chain where there were one shipping line and two forwarders providing transportation service between two ports, and the potential demands were given in advance. A mathematical model was constructed to analyze how the pricing and empty equipment repositioning decisions were made by the shipping lines and forwarders. The results showed that whether pricing policies were established, the cargo demands mainly depended on the potential demand imbalance between the two ports. Regarding the empty equipment repositioning sharing strategy, the result showed that there was a threshold determining which party should undertake the repositioning costs.
Regarding the issue of container sharing in or across alliances. Tong and Yan [25] examined the potential cooperation plans in empty container repositioning across alliances. An empty pool repositioning system was proposed in which after an alliance was established, members could provide their surplus containers to other members who were experiencing deficits. Zheng et al. [34] proposed a two-stage optimization method for studying an empty container allocation problem considering the coordination of shipping lines. In the two-stage approach, the first stage determined a centralized optimization solution for empty container allocation, and the exchange costs at different ports were estimated based on the solution obtained in the first stage. The numerical experiments showed the effectiveness of the proposed method.

After reviewing the above literature regarding the empty container repositioning problem, this paper summarizes the observations as follows: (1) in most of the literature, the empty container repositioning issue is considered as a cargo allocation problem that is commonly formulated as a network flow problem; and (2) the container sharing strategy is seldom discussed in this field. To the best of our knowledge, there is only one research, which was published by Zheng et al. [34], that developed an optimization model for the empty container allocation problem considering the coordination among shipping lines. The difference between our work and the literature [34] is that Zheng et al. [34] proposed a two-phase model to study the empty container repositioning problem and there were only the shipping lines considered in the problem while our work focuses on investigating the relationship between the empty container matching platform company and a group of shipping lines. Further, in our research, a bilevel programming model is proposed to study the pricing problem of exchange fee at the deficit ports and the empty container repositioning problem among shipping lines.

Therefore, mainly based on the idea of container sharing, this paper proposes a new solution framework with a bilevel structure for the empty container repositioning problem considering sharing and exchanging strategies. In the proposed framework, a matching platform company providing empty container matching services and a group of shipping lines in a given maritime transportation network are considered. The purposes of the bilevel problem are to maximize the profits of the matching platform company and to minimize 
the repositioning costs of shipping lines. How the exchange costs at different ports are determined to achieve both objectives is the question addressed by this paper.

\section{Solution approach}

In this section, we first formally define the problem, followed by a detailed formulation. The solution approach proposed to tackle this problem is then presented based on the mathematical features of the formulation.

\subsection{Problem statement}

The purpose of this research is to investigate the pricing in the empty container exchanging and empty container repositioning problem to address empty container sharing in the maritime industry. In the pricing problem, an empty container matching platform company provides matching services for the shipping lines within a given maritime network. The matching platform company determines the price of empty container exchange at each port to maximize the profit of the matching platform company. In addition, the shipping lines determine their empty container dispatching strategies based on the exchange fees and the surplus and deficit conditions of empty containers at each port. The goal of the overall framework is to determine the optimal price for each deficit port to promote the exchange activities such that the utilization of empty containers in a group of shipping lines can be maximized. In such framework, the matching platform company can maximize its profit while the shipping lines can be cost-effective based on the price determined by the platform. The empty container matching service can effectively increase the utilization rate of empty containers and reduce the empty container repositioning costs, which are beneficial for both exchanges. An example is illustrated in Fig. 1. When there is a situation where the

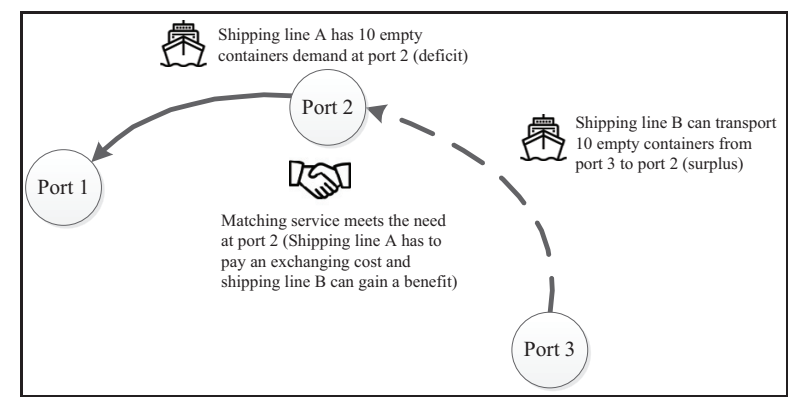

Fig. 1. An example about how an exchange activity conducted. empty container condition for shipping line A at port 2 is a deficit and shipping line B can transport surplus containers to port 2 through its shipping route or shipping line $B$ has the surplus containers at port 2, through the matching platform service, the empty containers of shipping line $B$ can be exchanged with shipping line $A$ at port 2. Shipping line A has to pay an exchange fee for the matching platform service while shipping line $B$ gains a benefit from the exchange activities. Note that the rental cost is not considered in this problem. The main idea of this research is to apply the sharing economy concept to the empty container repositioning problem. Therefore, the members participating in a group, which can be considered as a kind of alliance, share their resources of empty containers to other members in this group. Based on this condition, to promote exchange activities, this paper applies a mechanism, in which a shipping line (line $\mathrm{A}$ in the example) has to pay an exchange cost to obtain the required containers from the other lines, and another shipping line (line B in the example) can gain a benefit from the removal. In this case, line A chooses to pay the exchange cost to satisfy its deficit because it is more cost-effective than transporting containers from its own surplus ports which is far from the deficit port. With the container matching services, shipping lines can achieve more flexible container use and choose a more cost-effective way to conduct empty container repositioning.

In this research, the matching platform company determines the empty container exchange fee at each port, and the shipping lines determine the dispatch plan of empty containers according to the exchange fee and the surplus and deficit conditions of empty containers at each port. There is a leader and follower relationship between the matching platform company and the shipping lines in which the dispatching plans of shipping lines vary according to the exchange fees at each port; therefore, the matching platform company should consider the impact of the exchange fees on the shipping lines' behaviors when the exchange fees are determined to maximize its profits. The interactive relationship between the two parties in the studied problem is the same as the situation of two competitors in a Stackelberg game where one competitor (i.e., the leader) moves first and the other (i.e., the follower) moves after the leader [22]. Consequently, the proposed problem is said to be a Stackelberg game and formulated as a bilevel programming problem to connect the interactive relationship between the matching platform company and the shipping lines to optimize the overall problem. 
In the bilevel structure, the pricing problem of the matching platform company is set to be the upperlevel problem (leader) of the model. The objective is to maximize the profit of the matching platform company. A set of subproblems in which each shipping line determines its repositioning plan is constructed as the lower-level problem (followers) of the model. It aims to minimize the total dispatch costs while considering the flow conservation restriction of empty container repositioning in a given maritime transportation network. When the matching platform company sets the exchange fee of empty containers in the upper-level problem, the impact on the empty container repositioning plan of shipping lines in the lower-level problem should be considered in the profit maximization of the overall problem. Therefore, this research constructs this problem as a bilevel mathematical programming model and regards the lower-level problem as the constraint of the upper-level problem. The model structure is as follows:

Maximize Profits of the matching platform company
subject to Fee setting limit
Minimize Total repositioning costs for shipping line $\mathrm{i}$
subject to Flow conservation restriction for shipping
line $\mathrm{i}$
where $i=1,2, \ldots, L$

\subsection{Assumptions}

First, the basic hypotheses are established for the proposed problem to clarify the scope and limitations of this research. The time dimension has to be considered when an empty container repositioning model is constructed. However, if the divisions of time are excessively exact, the complexity of the problem can increase significantly, which makes the problem difficult to solve. This research focuses on exploring the relationship between the pricing and repositioning problems of the matching platform company and the shipping lines. Therefore, the exact time dimension and the constraint for the available space of container ships are not considered in the proposed model. Alternatively, according to Zheng et al. [34], in a practical ship route, the service frequency is usually one week. To simplify the problem, this research assumes that the service frequency of ship routes is fixed with one week unit. Moreover, based on Christiansen et al. [4], it is common for shipping lines and shippers to conduct business under long-term contracts. For some shipping lines, long-term contracts account for $80-95 \%$ of their overall operations. Therefore, this research assumes that the shipping demands of shipping lines at each port are predetermined, fixed and not affected by uncertain factors. The surplus and deficit conditions of empty containers then can be obtained through the given weekly demand of each shipping line. Moreover, the assumption that the total supply of empty containers is greater than the total demand of empty containers is made in this research to ensure the feasibility of the proposed model. Furthermore, in the empty container repositioning model, it is assumed that all the shipping lines can obtain the complete information of the given maritime transport network and they will adopt the repositioning plan that can benefit themselves the most without being affected by uncertain factors.

\subsection{Mathematical formulation}

Before presenting the bilevel mathematical programming model, the notations are first defined as follows.

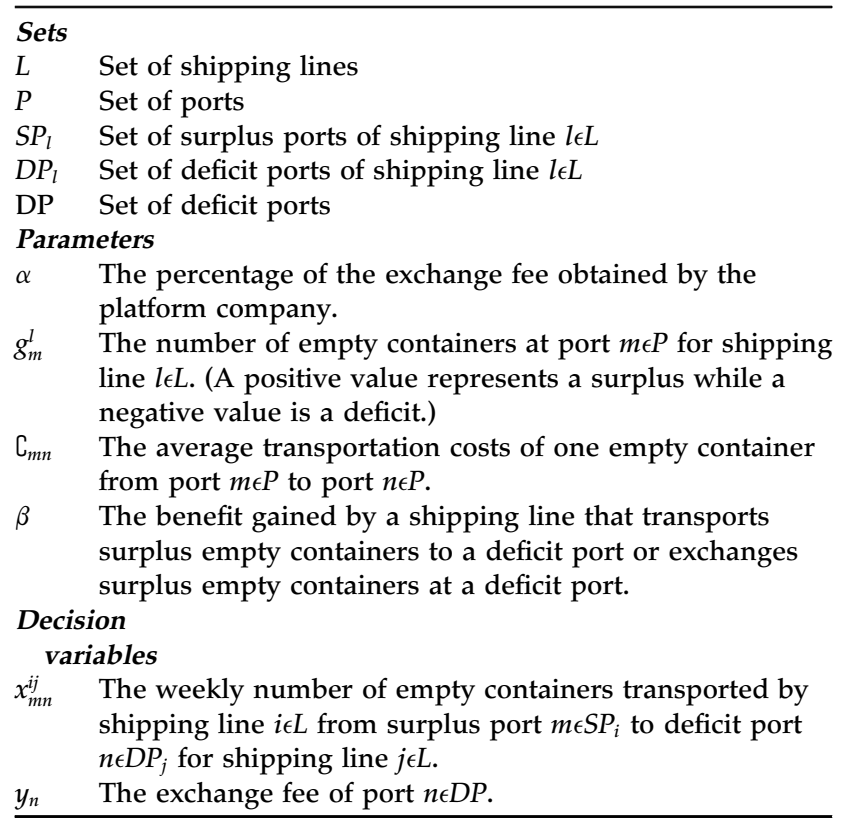

Based on the definitions of sets, parameters and decision variables, we present the following upperlevel and lower-level program in the bilevel programming formulation.

\subsubsection{Upper-level model}

$$
\text { Maximize } \sum_{i \in L} \sum_{j \in L, j \neq i} \sum_{m \in S P_{i}} \sum_{n \in D P_{j}} x_{m n}^{i j} \times\left(\alpha \times y_{n}-\beta\right)
$$


Subject to

$y_{n} \geq 0, \forall n \in D P$

The matching platform company aims to maximize its profits by properly setting prices. Constraint (1) is the objective function of the upperlevel model. There are two terms in the objective function. The first one is the revenue generated from the lines who choose to exchange containers at their deficit ports so that they should pay the exchange fees to the platform company $\left(\sum_{i \in L} \sum_{j \in L, j \neq i} \sum_{m \in S P_{i}} \sum_{n \in D P_{j}} x_{m n}^{i j} \times \quad \alpha \times \quad y_{n}\right)$. The second term is a negative term $\left(\sum_{i \in L} \sum_{j \in L, j \neq i} \sum_{m \in S P_{i}} \sum_{n \in D P_{j}} x_{m n}^{i j} \times \beta\right)$, which is designed to promote the exchange activities. The platform company has to pay the fee, $\beta$ to lines who conduct the exchange activities that satisfy the demand at the deficit ports. Constraint (2) is a non-negative constraint.

\subsubsection{Lower-level model}

$$
\begin{aligned}
& \text { Minimize } \sum_{j \in L} \sum_{m \in S P_{i}} \sum_{n \in D P_{j}} x_{m n}^{i j} \times \complement_{m n}+\sum_{j \in L, j \neq i} \sum_{m \in S P_{j}} \sum_{n \in D P_{i}} x_{m n}^{j i} \\
& \times y_{m}-\sum_{j \in L, j \neq i m \in S P_{i} n \in D P_{j}} \sum_{m n}^{i j} \times \beta
\end{aligned}
$$

Subject to

$\sum_{j \in L} \sum_{n \in D P_{j}} x_{m n}^{i j} \leq g_{m}^{i}, \quad \forall m \epsilon S P_{i}$

$\sum_{j \in L} \sum_{m \in S P_{j}} x_{m n}^{j i}=-g_{n}^{i}, \quad \forall n \in D P_{i}$

$x_{m n}^{i j} \geq 0, \forall m, n \in P, \forall i, j \in L$

where $i=1,2, \ldots, L$.

In the lower-level model, the repositioning plans of the shipping lines for empty containers are made according to the exchange fee and the surplus and deficit condition at each port. Note that the decision maker of the lower level problem is a group of shipping lines in the given shipping network who make their own plan to make the supply/demand meet based on the exchange fees determined by the platform company. Therefore, there is a set of subproblems $\left(\min \left\{f(x)_{i}: x \in S\right\}, \forall\right.$ $i=1,2, \ldots, L$, where $S$ is the constraint region) in the lower level problem. The objective function (3) aims to minimize the total repositioning costs. The total costs mainly consist of three parts: the average transportation costs of repositioning, the exchange fees paid to the matching company, and the benefits gained from conducting the exchange activities. Constraints (4) and (5) ensure the flow conservation restriction of empty container repositioning in a given maritime transportation network. Constraint (4) establishes that the total number of empty containers transported from a surplus port cannot exceed its surplus. Constraint (5) ensures that the demand for empty containers at a deficit port can be met after repositioning. Constraint (6) is a non-negative constraint. As constraints (1) to (6) correspond to a bilevel programming problem, which is difficult to solve directly, we attempt to transform it into a single level program in the following. Note that in a general traffic assignment problem, to explore the core strategy of the research, the traffic flow is usually considered as a continuous decision variable instead of a discrete one. This research focuses on exploring the interactive relationship between the pricing of container exchanging and container repositioning. Under this consideration, the empty container transportation volume in the maritime transportation network is considered to be a continuous variable.

\subsection{Karush-Kuhn-Tucker (KKT) conditions}

In a bilevel programming problem, the KKTbased approach is one of the most successful solution methods. As indicated in Gumus and Floudas [10], in a bilevel programming problem, the lowerlevel problem can be replaced with its equivalent KKT conditions and become the constraints of the upper-level problem. Consequently, the resulting formulation is a single level problem and can be solved efficiently by developing a proper algorithm. The bilevel model proposed in Section 3 shows that there is a set of multiple sub problems (followers) contained in the lower-level problem. This research applies an extended KKT approach based on Lu et al. [15] to the bilevel problem with multiple followers. To deal with the bilevel decision problem, the fundamental idea of the extended Kuhn-Tucker approach is to replace each follower's problem with its equivalent KKT conditions and add the generated conditions into the leader's problem [15].

Furthermore, only when the lower-level problem is convex are the KKT optimality conditions necessary and sufficient for guaranteeing the optimum in the lower-level problem. We next show the convexity of the lower-level problem in the proposed 
bilevel formulation. To show the convexity, the objective function of the lower-level problem constraint (3) has to be proven to be convex. We can derive the Hessian matrix of the objective function of the lower-level problem as follows.

$H=\left[\begin{array}{ccc}\frac{\partial^{2} f}{\partial x_{11}^{11^{2}}} & \cdots & \frac{\partial^{2} f}{\partial x_{11}^{11} \partial x_{m n}^{i j}} \\ \vdots & \ddots & \vdots \\ \frac{\partial^{2} f}{\partial x_{m n}^{i j} \partial x_{11}^{11}} & \cdots & \frac{\partial^{2} f}{\partial x_{m n}^{i j}{ }^{2}}\end{array}\right]$

Since the first-order derivative of the lowerlevel objective function with respect to each variable is constant $\left(\complement_{m n}+y_{n}-\beta, \forall m, n, i, j\right)$, the determinants of any submatrix in the Hessian equals zero and the Hessian is positive semidefinite. Based on Arora [1], if the objective function is a convex function defined on a convex feasible set, the KKT conditions are sufficient and necessary for a global optimum solution. Since the objective function of the lowerlevel problem is proven to be convex and the constraints are linear, the KKT conditions are equivalent to the lower-level optimization problem, and the KKT optimality conditions for the lower-level problem proposed in Section 3.3 are derived as follows. We first dualize the lower-level constraints into the following function. $\sum_{j \in L} \sum_{n \in D P_{j}} x_{m n}^{i j}-g_{m}^{i} \leq 0, \quad \forall i \epsilon L, \forall m \epsilon S P_{i}$

$\sum_{j \in L} \sum_{m \in S P_{j}} x_{m n}^{j i}+g_{n}^{i}=0, \forall i \epsilon L, \quad \forall n \in D P_{i}$

$-x_{m n}^{i j} \leq 0, \quad \forall m, n, i, j$

$u_{i, m} \times\left(\sum_{j \in L} \sum_{n \in D P_{j}} x_{m n}^{i j}-g_{m}^{i}\right)=0, \quad \forall i \epsilon L, \forall m \epsilon S P_{i}$

$\omega_{m n}^{i j} \times\left(-x_{m n}^{i j}\right)=0, \quad \forall m, n, i, j$

$u_{i, m} \geq 0, \forall i \epsilon L, \quad \forall m \in S P_{i}$

$\omega_{m n}^{i j} \geq 0, \quad \forall m, n, i, j$

Constraint (9) is the stationarity condition corresponding to the decision variables in the lowerlevel problem. Constraints (10)-(12) ensure the primal feasibility. Constraints (13) and (14) are the complementary slackness conditions. Constraints (15) and (16) hold the dual feasibility. Constraints (9)-(16) are equivalent to the KKT optimality condition of the lower level program and hence can replace constraints (3)-(6) in the original formulation.

After the lower problem is transformed as the KKT optimality conditions, the active set strategy

$$
\begin{gathered}
L_{i}\left(y_{n}, x_{m n}^{i j}, u_{i, m}, v_{i, n}, \omega_{m n}^{i j}\right)=\sum_{j \in L} \sum_{m \in S P_{i}} \sum_{n \in D P_{j}} x_{m n}^{j i} \times \complement_{m n}+\sum_{j \in L, j \neq i} \sum_{m \in S P_{j}} \sum_{n \in D P_{i}} x_{m n}^{j i} \times y_{m}-\sum_{j \in L, j \neq i} \sum_{m \in S P_{i}} \sum_{n \in D P_{j}} x_{m n}^{i j} \times \beta+u_{i, m} \\
\times\left(\sum_{j \in L} \sum_{n \in D P_{j}} x_{m n}^{i j}-g_{m}^{i}\right)+v_{i, n} \times\left(\sum_{j \in L} \sum_{m \in S P_{j}} x_{m n}^{j i}+g_{n}^{i}\right)+\omega_{m n}^{i j} \times\left(-x_{m n}^{i j}\right)
\end{gathered}
$$

where $i=1,2, \ldots, L$.

Constraint (8) is the Lagrangian function corresponding to the lower-level problem, where $u_{i, m}, v_{j, n}$, and $\omega_{m n}^{i j}$ are the KKT multiplier variables associated with constraints (4), (5) and (6), respectively. To ensure an optimal solution for the original bilevel problem, $\left(y_{n}, x_{m n}^{i j}, u_{i, m}, v_{i, n}, \omega_{m n}^{i j}\right)$, the following necessary and sufficient conditions must to be satisfied by $\left(x_{m n}^{i j}, u_{i, m}, v_{i, n}, \omega_{m n}^{i j}\right)$ at a fixed $y_{n}$.

$\nabla_{x_{m n}} \cdot L_{i}\left(y_{n}, x_{m n}^{i j}, u_{i, m}, v_{i, n}, \omega_{m n}^{i j}\right)=0, \quad \forall m, n \in P, \forall i, j \in L$ technique can be employed to replace the complementary slackness constraints in the KKT conditions. The complementary slackness constraints are the most difficult parts in solving the KKT conditions. Based on Grossmann and Floudas [9], in the active set strategy, a binary variable, $Z_{k}$, that is associated with each complementary constraint $k$ and chooses which set of constraints in the complementary conditions would be active is introduced. The complementary slackness constraints $\left(u_{k} \cdot q_{k}=0, \quad \forall k\right)$ can be transformed as follows.

$u_{k}-M \cdot Z_{k} \leq 0, \quad \forall k$ 
$q_{k}-M \cdot\left(1-Z_{k}\right) \leq 0, \quad \forall k$

$u_{k}, q_{k} \geq 0, \quad \forall k$

$Z_{k} \in\{0,1\}, \forall k$

where $u_{k}$ is the multiplier of constraint $q_{k}$ in the lower problem, and $M$ is a large number.

By employing the KKT approach and the active set strategy, we can transform the original bilevel formulation (constraints (1)-(6)) into a single level mix-integer quadratic problem (constraints (1)-(2) and constraints (9)-(16)) where the objective function is second order polynomial terms and the constraints are linear. The complete single level problem is showed as follows.

Maximize $\sum_{i \in L} \sum_{j \in L, j \neq i} \sum_{m \in S P_{i}} \sum_{n \in D P_{j}} x_{m n}^{i j} \times\left(\alpha \times y_{n}-\beta\right)$

Subject to

$y_{n} \geq 0, \quad \forall n \in D P$

$\nabla_{x_{m n}^{i j}} \cdot L_{i}\left(y_{n}, x_{m n}^{i j}, u_{i, m}, v_{i, n}, \omega_{m n}^{i j}\right)=0, \quad \forall m, n \in P, \forall i, j \in L$

$\sum_{j \in L} \sum_{n \in D P_{j}} x_{m n}^{i j}-g_{m}^{i} \leq 0, \forall i \epsilon L, \forall m \in S P_{i}$

$\sum_{j \in L} \sum_{m \in S P_{j}} x_{m n}^{j i}+g_{n}^{i}=0, \quad \forall i \epsilon L, \quad \forall n \in D P_{i}$

$-x_{m n}^{i j} \leq 0, \quad \forall m, n, i, j$

$u_{k}-M \cdot Z_{i, m} \leq 0, \quad \forall i, m$

$\left(-\sum_{j \in L} \sum_{n \in D P_{j}} x_{m n}^{i j}+g_{m}^{i}\right)-M \cdot\left(1-Z_{i, m}\right) \leq 0, \quad \forall i, m$

$\omega_{m n}^{i j}-M \cdot Q_{i, j, m, n} \leq 0, \quad \forall i, j, m, n$

$x_{m n}^{i j}-M \cdot\left(1-Q_{i, j, m, n}\right) \leq 0, \quad \forall i, j, m, n$

$Z_{i, m}, Q_{i, j, m, n} \in\{0,1\}$

$u_{i, m} \geq 0, \quad \forall i \in L, \forall m \in S P_{i}$

$\omega_{m n}^{i j} \geq 0, \forall m, n, i, j$

Note that in the primal bilevel problem, there is no quadratic formulation since the decision variables of the upper-level (lower-level) problem are the parameters of the lower-level (upper-level) problem. Note that the quadratic formulation is formed only when the bilevel problem is transformed into a single level problem. The decision variables of the upper-level and lower-level problems (i.e., $x_{m n}^{i j}$ and $y_{n}$, respectively) form the quadratic formulation in the objective function of the upper-level problem.

\section{Numerical experiment}

In this section, the proposed solution framework is empirically applied to the instance revised from the realistic data. The proposed bilevel programming model is solved by using the commercial optimization package Gurobi ${ }^{\circledR} 9.0 .3$, and all the procedures are implemented in the C\# programming language and performed on a Windows-based machine with a $1.8 \mathrm{GHz} \mathrm{CPU}$ processor and $8 \mathrm{~GB}$ of RAM.

\subsection{Data description}

To validate the proposed empty container sharing strategy, a practical Asia-Europe-Oceania shipping network that consists of 46 major ports in Asia and Europe [16] is applied to the numerical experiments, as shown in Fig. 2.

Furthermore, there are three shipping lines (shipping line 1, shipping line 2, and shipping line 3) considered in the numerical experiment to estimate the effectiveness of the proposed solution strategy. The origin-destination pairs of weekly shipping demands for the shipping lines are generated based on the data provided by Zheng et al. [34]. To obtain the average transportation costs between two ports, this research simply considers the container ships with a capacity of 5000 TEUs used by the shipping lines. According to Stopford [23], the bunker costs account for most of the ship operating costs; therefore, this research assumes that the bunker costs between two ports represent the average transportation cost, $\complement_{m n}$, from port $m$ to port $n$; and based on Brouer et al. [2], the bunker costs can be calculated as $\complement_{m n}=0.03 \times$ Distance $_{m n}(\mathbf{n}$ mile $)$. Moreover, in this study, to promote exchange activities, we assume that there is an exchange benefit, $\beta$ for shipping lines who conduct exchange activities that satisfy the demand at the deficit ports. Therefore, the price of deficit ports is affected by the value of $\beta$. That means when the value of $\beta$ is greater, the price of deficit ports becomes greater. In current research, we focus on studying the relationship between the 


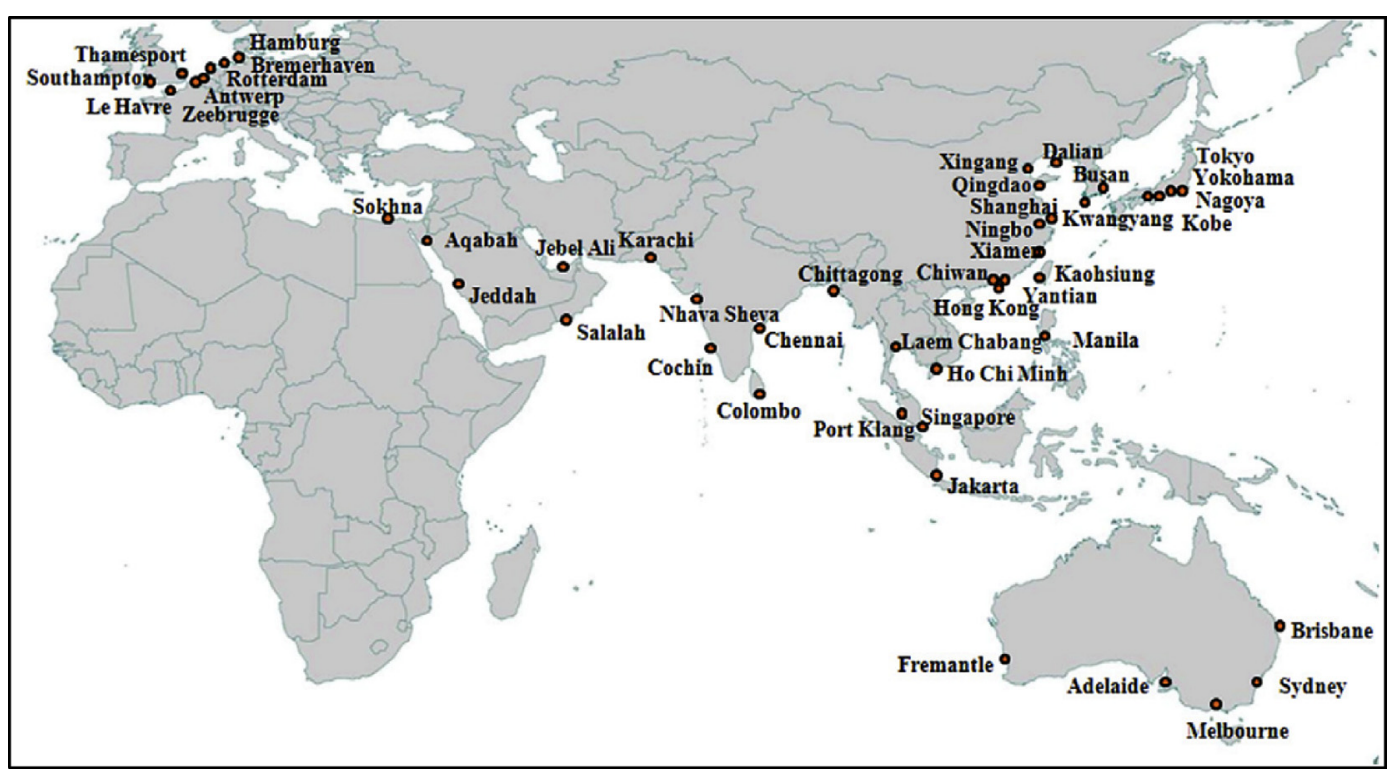

Fig. 2. Asia-Europe-Oceania shipping network [16].

pricing and repositioning problems. Therefore, this study only sets a constant value for $\beta(600 \$ /$ container) which can make the resulting price sensible. Furthermore, the percentage of the exchange fee obtained by the platform company, $\alpha$ is set as 1.4 in this numerical experiment.

\subsection{Numerical results}

In the first numerical experiment, two scenarios (Scenario 1 and Scenario 2) are set to validate the effectiveness of the proposed container sharing strategy and explore the advantage of container exchanging within the maritime transportation network. In Scenario 1, the shipping lines apply the container sharing strategy; and in Scenario 2, the shipping lines do not apply the container sharing strategy that means each shipping line has to meet its demand by transporting empty containers from its own surplus ports to its deficit ports. If the deficit is greater than the surplus, a penalty is given per container (600\$/container). The results are shown in Table 1.
Since the total costs for the shipping lines in the lower-level problem mainly consist of three parts, including the transportation costs of repositioning, the exchange fees paid for the matching company, and the benefits gained from conducting the exchange activities, the total empty container repositioning costs for shipping lines is the sum of the three terms. In Scenario 1, the total empty container repositioning costs for shipping lines 1, 2, and 3 are $15.98,16.23$ and $6.23\left(10^{5} \$\right)$, respectively. However, for Scenario 2, the shipping lines do not adopt the sharing strategy, and thus the shipping lines have to transport their empty containers from the surplus port to the deficit port by themselves or lease containers, which considerably increases the costs. Although the transportation costs of shipping lines 1 and 3 in Scenario 1 (15.98 and 6.23) are greater than the costs in Scenario 2 (14.30 and 3.11), the total empty container repositioning costs are lower by considering the sharing strategy (10.41 and 2.65). Moreover, the total transportation cost of all the shipping lines in Scenario 1 (38.44) is lower than the cost in Scenario 2 (59.81). The results show

Table 1. Comparison between two scenarios.

\begin{tabular}{|c|c|c|c|c|c|c|}
\hline & \multicolumn{3}{|l|}{ Scenario 1} & \multicolumn{3}{|l|}{ Scenario 2} \\
\hline & Shipping line 1 & Shipping line 2 & Shipping line 3 & Shipping line 1 & Shipping line 2 & Shipping line 3 \\
\hline Transportation cost, $C_{m n}\left(10^{5} \$\right)$ & 15.98 & 16.23 & 6.23 & 14.30 & 42.42 & 3.11 \\
\hline Exchange cost, $y_{n}\left(10^{5} \$\right)$ & 23.51 & 26.22 & 15.67 & - & - & - \\
\hline Exchange benefit, $\beta\left(10^{5} \$\right)$ & 29.08 & 32.77 & 19.28 & - & - & - \\
\hline Total cost $\left(10^{5} \$\right)\left(C_{m n}+y_{n}-\beta\right)$ & 10.41 & 9.68 & 2.65 & 14.30 & 42.42 & 3.11 \\
\hline Objective value $\left(10^{5} \$\right)$ & \multicolumn{3}{|c|}{3.92} & \multicolumn{3}{|c|}{-} \\
\hline
\end{tabular}


Table 2. The assignment of empty containers between the shipping lines.

\begin{tabular}{|c|c|c|c|c|c|c|c|c|c|c|c|c|c|c|}
\hline$i$ & $j$ & $m$ & $n$ & $x_{m n}^{i j}$ & $i$ & $j$ & $m$ & $n$ & $x_{m n}^{i j}$ & $i$ & $j$ & $m$ & $n$ & $x_{m n}^{i j}$ \\
\hline 0 & 0 & 2 & 20 & 583 & 1 & 0 & 4 & 37 & 107 & 2 & 0 & 2 & 15 & 69 \\
\hline 0 & 0 & 2 & 29 & 22 & 1 & 0 & 7 & 17 & 759 & 2 & 0 & 3 & 12 & 42 \\
\hline 0 & 0 & 3 & 13 & 98 & 1 & 0 & 7 & 21 & 24 & 2 & 0 & 3 & 35 & 48 \\
\hline 0 & 0 & 3 & 17 & 97 & 1 & 0 & 8 & 16 & 201 & 2 & 0 & 7 & 15 & 324 \\
\hline 0 & 0 & 3 & 39 & 186 & 1 & 0 & 10 & 13 & 218 & 2 & 0 & 12 & 10 & 119 \\
\hline 0 & 0 & 4 & 11 & 5 & 1 & 0 & 12 & 41 & 39 & 2 & 0 & 14 & 19 & 95 \\
\hline 0 & 0 & 4 & 15 & 337 & 1 & 0 & 14 & 17 & 463 & 2 & 0 & 16 & 18 & 358 \\
\hline 0 & 0 & 4 & 18 & 166 & 1 & 0 & 16 & 18 & 69 & 2 & 0 & 23 & 24 & 5 \\
\hline 0 & 0 & 5 & 13 & 128 & 1 & 0 & 16 & 30 & 18 & 2 & 0 & 23 & 45 & 151 \\
\hline 0 & 0 & 6 & 15 & 87 & 1 & 0 & 16 & 43 & 262 & 2 & 1 & 0 & 21 & 71 \\
\hline 0 & 0 & 23 & 34 & 48 & 1 & 0 & 22 & 11 & 392 & 2 & 1 & 4 & 17 & 288 \\
\hline 0 & 0 & 25 & 11 & 31 & 1 & 0 & 22 & 12 & 17 & 2 & 1 & 4 & 40 & 361 \\
\hline 0 & 0 & 25 & 14 & 249 & 1 & 0 & 22 & 45 & 73 & 2 & 1 & 12 & 9 & 187 \\
\hline 0 & 0 & 26 & 11 & 652 & 1 & 0 & 25 & 17 & 418 & 2 & 1 & 13 & 30 & 14 \\
\hline 0 & 0 & 26 & 27 & 4 & 1 & 0 & 25 & 34 & 28 & 2 & 1 & 22 & 37 & 261 \\
\hline 0 & 0 & 32 & 41 & 121 & 1 & 0 & 26 & 17 & 22 & 2 & 1 & 24 & 32 & 171 \\
\hline 0 & 0 & 38 & 7 & 19 & 1 & 0 & 26 & 18 & 271 & 2 & 1 & 25 & 19 & 148 \\
\hline 0 & 1 & 0 & 6 & 299 & 1 & 0 & 29 & 36 & 5 & 2 & 1 & 26 & 5 & 227 \\
\hline 0 & 1 & 0 & 45 & 90 & 1 & 0 & 35 & 34 & 86 & 2 & 1 & 29 & 30 & 138 \\
\hline 0 & 1 & 1 & 15 & 385 & 1 & 0 & 43 & 10 & 105 & 2 & 1 & 34 & 41 & 61 \\
\hline 0 & 1 & 4 & 1 & 136 & 1 & 1 & 0 & 21 & 165 & 2 & 1 & 35 & 33 & 28 \\
\hline 0 & 1 & 4 & 9 & 194 & 1 & 1 & 0 & 30 & 48 & 2 & 1 & 43 & 17 & 43 \\
\hline 0 & 1 & 4 & 13 & 9 & 1 & 1 & 2 & 36 & 172 & 2 & 2 & 8 & 17 & 205 \\
\hline 0 & 1 & 4 & 20 & 200 & 1 & 1 & 3 & 13 & 35 & 2 & 2 & 10 & 11 & 72 \\
\hline 0 & 1 & 5 & 28 & 64 & 1 & 1 & 3 & 19 & 236 & 2 & 2 & 12 & 5 & 177 \\
\hline 0 & 1 & 8 & 9 & 202 & 1 & 1 & 4 & 21 & 335 & 2 & 2 & 14 & 37 & 119 \\
\hline 0 & 1 & 23 & 6 & 65 & 1 & 1 & 4 & 37 & 63 & 2 & 2 & 23 & 31 & 64 \\
\hline 0 & 1 & 23 & 33 & 409 & 1 & 1 & 4 & 39 & 104 & 2 & 2 & 24 & 18 & 79 \\
\hline 0 & 1 & 26 & 17 & 1029 & 1 & 1 & 4 & 44 & 538 & 2 & 2 & 26 & 20 & 66 \\
\hline 0 & 1 & 28 & 42 & 107 & 1 & 1 & 8 & 11 & 216 & 2 & 2 & 26 & 36 & 66 \\
\hline 0 & 1 & 33 & 37 & 96 & 1 & 1 & 8 & 18 & 5 & 2 & 2 & 38 & 32 & 13 \\
\hline 0 & 1 & 38 & 9 & 93 & 1 & 1 & 8 & 31 & 194 & - & - & - & - & - \\
\hline 0 & 1 & 42 & 27 & 66 & 1 & 1 & 12 & 15 & 558 & - & - & - & - & - \\
\hline 0 & 1 & 44 & 30 & 146 & 1 & 1 & 12 & 33 & 13 & - & - & - & - & - \\
\hline 0 & 2 & 0 & 1 & 45 & 1 & 1 & 12 & 41 & 226 & - & - & - & - & - \\
\hline 0 & 2 & 0 & 37 & 87 & 1 & 1 & 16 & 18 & 231 & - & - & - & - & - \\
\hline 0 & 2 & 2 & 6 & 121 & 1 & 1 & 16 & 27 & 161 & - & - & - & - & - \\
\hline 0 & 2 & 4 & 15 & 256 & 1 & 1 & 23 & 32 & 505 & - & - & - & - & - \\
\hline 0 & 2 & 4 & 21 & 130 & 1 & 1 & 24 & 21 & 197 & - & - & - & - & - \\
\hline 0 & 2 & 9 & 15 & 191 & 1 & 1 & 26 & 5 & 263 & - & - & - & - & - \\
\hline 0 & 2 & 23 & 40 & 5 & 1 & 1 & 26 & 30 & 392 & - & - & - & - & - \\
\hline 0 & 2 & 31 & 21 & 126 & 1 & 1 & 26 & 42 & 128 & - & - & - & - & - \\
\hline 0 & 2 & 40 & 17 & 220 & 1 & 1 & 29 & 37 & 199 & - & - & - & - & - \\
\hline 0 & 2 & 40 & 27 & 76 & 1 & 1 & 34 & 6 & 185 & - & - & - & - & - \\
\hline- & - & - & - & - & 1 & 1 & 38 & 6 & 38 & - & - & - & - & - \\
\hline- & - & - & - & - & 1 & 1 & 43 & 36 & 26 & - & - & - & - & - \\
\hline- & - & - & - & - & 1 & 2 & 2 & 39 & 34 & - & - & - & - & - \\
\hline- & - & - & - & - & 1 & 2 & 7 & 13 & 15 & - & - & - & - & - \\
\hline- & - & - & - & - & 1 & 2 & 7 & 41 & 96 & - & - & - & - & - \\
\hline- & - & - & - & - & 1 & 2 & 7 & 42 & 78 & - & - & - & - & - \\
\hline- & - & - & - & - & 1 & 2 & 12 & 32 & 212 & - & - & - & - & - \\
\hline- & - & - & - & - & 1 & 2 & 13 & 9 & 21 & - & - & - & - & - \\
\hline- & - & - & - & - & 1 & 2 & 13 & 28 & 21 & - & - & - & - & - \\
\hline- & - & - & - & - & 1 & 2 & 14 & 44 & 179 & - & - & - & - & - \\
\hline- & - & - & - & - & 1 & 2 & 16 & 6 & 128 & - & - & - & - & - \\
\hline- & - & - & - & - & 1 & 2 & 16 & 9 & 204 & - & - & - & - & - \\
\hline- & - & - & - & - & 1 & 2 & 22 & 33 & 150 & - & - & - & - & - \\
\hline- & - & - & - & - & 1 & 2 & 22 & 45 & 30 & - & - & - & - & - \\
\hline- & - & - & - & - & 1 & 2 & 23 & 40 & 155 & - & - & - & - & - \\
\hline- & - & - & - & - & 1 & 2 & 24 & 30 & 353 & - & - & - & - & - \\
\hline- & - & - & - & - & 1 & 2 & 29 & 17 & 28 & - & - & - & - & - \\
\hline- & - & - & - & - & 1 & 2 & 29 & 19 & 181 & - & - & - & - & - \\
\hline
\end{tabular}




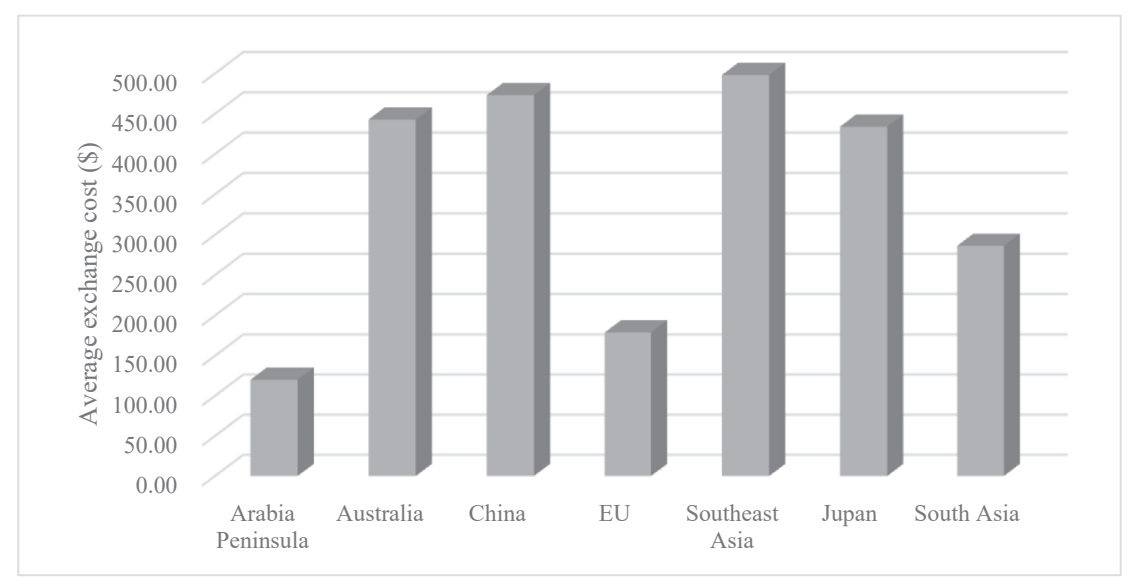

Fig. 3. Average empty container exchange costs of the deficit ports in different regions.

the advantage of adopting the container sharing strategy in the shipping market. The detailed assignment of empty containers between the shipping lines adopting the exchanging strategy is shown in Table 2.

The following part studies the results of the empty container exchange costs of the deficit ports. Fig. 3 shows the average empty container exchange costs of the deficit ports in different regions.

By comparing the exchange costs of the deficit ports in different regions, it can be found that the deficit ports in Asia have higher exchange costs, e.g., the average exchange costs of the ports in China, Japan, and Southeast Asia are 472.91, 433.88, and 498 (\$), respectively, while the average exchange costs of the ports in Europe are 178.83 (\$). The considerable difference is caused by the imbalance of the imports and the exports in the trade between Asia and Europe. Most of the empty containers are accumulated at the ports in Europe, which leads to the lower empty container exchange costs compared with the ports in Asia.

\section{Conclusions}

This paper investigates an empty container repositioning problem where a matching platform company provides empty container matching services for shipping lines within a given maritime transportation network. Because there is a leader and follower relationship between the matching platform company and the shipping lines, the studied problem is formulated as a bilevel programming problem. To solve the bilevel problem, a mathematical formulation with a bilevel structure is constructed, and a KKT approach is applied.
The results of numerical experiments show that (1) the shipping lines that adopt the container sharing strategy can decrease the costs of empty container repositioning comparing to the shipping lines without sharing strategy; (2) although two of the shipping lines get greater transportation costs by adopting the sharing strategy, the total transportation cost of all the shipping lines is lower than the cost of shipping lines without the sharing strategy; (3) the exchange costs for empty containers at the deficit ports are estimated; and (4) the imbalance condition of imports and exports between the trade of Asia and Europe can also be observed according to the exchange costs.

Since this paper focuses on demonstrating the core idea of the bilevel structure between a matching platform company and shipping lines for the coordination in empty container repositioning, there are some limitations in the proposed work. For example, the time dimension issue is simplified, the shipping demand is fixed, and only the bunker costs are considered in the operating costs in the proposed model. In future work, this research can be extended in many ways. First, there are several costs that have to be considered in the total operating costs, e.g., the bunker costs, the inventory costs, and the container handling costs. Second, the laden container routing problem and the capacities of ships have to be considered in the shipping network. Third, the setting of the benefit, $\beta$ is an important issue which should be considered as a decision variable which will be affected by the price of deficit ports, the exchange activities among lines, and the transportation cost. Finally, this research can also be extended by establishing a long-term repositioning plan considering the shipping routes with time windows to make the proposed strategy 
more practical for empty container repositioning in the maritime industry.

\section{Acknowledgement}

The authors acknowledge the Ministry of Science and Technology, Taiwan, R.O.C. for providing partial funding support under contract number MOST 108-2410-H-007-097-MY4. The contents of the article remain the sole responsibility of the authors.

\section{References}

[1] Arora JS. 4 - optimum design concepts. In: Arora JS, editor. Introduction to optimum design. second ed. San Diego: Academic Press; 2004. p. 83-174.

[2] Brouer BD, Alvarez JF, Plum CEM, Pisinger D, Sigurd MM. A base integer programming model and benchmark suite for liner-shipping network design. Transport Sci 2014;48(2): 281-312. https://doi.org/10.1287/trsc.2013.0471.

[3] Brouer BD, Pisinger D, Spoorendonk S. Liner shipping cargo allocation with repositioning of empty containers. Inform Sys Operat Res 2011;49(2):109-24. https://doi.org/10.3138/ infor.49.2.109.

[4] Christiansen M, Fagerholt K, Nygreen B, Ronen D. Handbooks in operations research and management science: transportation, North Holland. 2006.

[5] Crainic TG, Gendreau M, Dejax P. Dynamic and Stochastic models for the allocation of empty containers. Oper Res 1993; 41(1):102-26. https://doi.org/10.1287/opre.41.1.102.

[6] Cruijssen F, Cools M, Dullaert W. Horizontal cooperation in logistics: opportunities and impediments. Transport Res E Logist Transport Rev 2007;43(2):129-42. https://doi.org/ 10.1016/j.tre.2005.09.007.

[8] Furtado P, Frayret J-M. Proposal sustainability assessment of resource sharing in intermodal freight transport with agentbased simulation. IFAC-PapersOnLine 2015;48(3):436-41. https://doi.org/10.1016/j.ifacol.2015.06.120.

[9] Grossmann IE, Floudas CA. Active constraint strategy for flexibility analysis in chemical processes. Comput Chem Eng 1987;11(6):675-93. https://doi.org/10.1016/0098-1354(87) 87011-4.

[10] Gumus ZH, Floudas CA. Global optimization of nonlinear bilevel programming problems. J Global Optim 2001;20(1): 1-31. https://doi.org/10.1023/A:1011268113791.

[12] Kuzmicz KA, Pesch E. Approaches to empty container repositioning problems in the context of Eurasian intermodal transportation. Omega-Inter J Manag Sci 2019;85:194-213. https://doi.org/10.1016/j.omega.2018.06.004.

[13] Lee S, Moon I. Robust empty container repositioning considering foldable containers. Eur J Oper Res 2020;280(3): 909-25. https://doi.org/10.1016/j.ejor.2019.08.004.

[14] Long Y, Lee LH, Chew EP, Luo Y, Shao J, Senguta A, et al. Operation planning for maritime empty container repositioning. Inter J Industr Eng-Theo Appl Prac 2013;20(1-2): $141-52$.

[15] Lu J, Shi CG, Zhang GQ. On bilevel multi-follower decision making: general framework and solutions. Inf Sci 2006; 176(11):1607-27. https://doi.org/10.1016/j.ins.2005.04.010.

[16] Meng Q, Wang SA. Liner shipping service network design with empty container repositioning. Transport Res E Logist
Transport Rev 2011;47(5):695-708. https://doi.org/10.1016/ j.tre.2011.02.004.

[17] Moon I, Do Ngoc A-D, Konings R. Foldable and standard containers in empty container repositioning. Transport Res $\mathrm{E}$ Logist Transport Rev 2013;49(1):107-24. https://doi.org/ 10.1016/j.tre.2012.07.005.

[18] Moon I, Hong H. Repositioning of empty containers using both standard and foldable containers. Marit Econ Logist 2016;18(1):61-77. https://doi.org/10.1057/mel.2015.18.

[19] Shintani K, Imai A, Nishimura E, Papadimitriou S. The container shipping network design problem with empty container repositioning. Transport Res E Logist Transport Rev 2007;43(1):39-59. https://doi.org/10.1016/ j.tre.2005.05.003.

[20] Song D, Zhang J, Carter J, Field T, Marshall J, Polak J, et al. On cost-efficiency of the global container shipping network. Marit Pol Manag 2005;32(1):15-30. https://doi.org/10.1080/ 0308883042000176640.

[21] Song DP, Carter J. Empty container repositioning in liner shipping. Marit Pol Manag 2009;36(4):291-307. https:// doi.org/10.1080/03088830903056934.

[22] Stackelberg Hv. The theory of the market economy. London: William Hodge; 1952.

[23] Stopford M. Maritime Economics. Routledge; 2009.

[24] Theofanis S, Boile M. Empty marine container logistics: facts, issues and management strategies. Geojournal 2008;74(1):51. https://doi.org/10.1007/s10708-008-9214-0.

[25] Tong HF, Yan H. Equipment planning strategy for liners: empty container repositioning across alliances. Maritime Bus Rev 2018;3(1):89-106. https://doi.org/10.1108/Mabr-11-20170026.

[26] Tran NK, Haasis HD. Literature survey of network optimization in container liner shipping. Flex Serv Manuf J 2015; 27(2-3):139-79. https://doi.org/10.1007/s10696-013-9179-2.

[28] Wang K, Wang SA, Zhen L, Que XB. Ship type decision considering empty container repositioning and foldable containers. Transport Res E Logist Transport Rev 2017;108: 97-121. https://doi.org/10.1016/j.tre.2017.10.003.

[30] Xu L, Beamon B. Supply chain coordination and cooperation mechanisms: an attribute-based approach. J Supply Chain Manag 2006;42:4-12. https://doi.org/10.1111/j.1745493X.2006.04201002.x.

[31] Xu L, Govindan K, Bu XZ, Yin YL. Pricing and balancing of the sea-cargo service chain with empty equipment repositioning. Comput Oper Res 2015;54:286-94. https://doi.org/ 10.1016/j.cor.2014.03.001.

[32] Zhang RY, Huang C, Feng XH. Empty container repositioning with foldable containers in a river transport network considering the limitations of bridge heights. Transport Res Pol Pract 2020;133:197-213. https://doi.org/10.1016/ j.tra.2020.01.019.

[33] Zhang SZ, Ruan X, Xia YZ, Feng XH. Foldable container in empty container repositioning in intermodal transportation network of Belt and Road Initiative: strengths and limitations. Marit Pol Manag 2018;45(3):351-69. https://doi.org/ 10.1080/03088839.2017.1400699.

[34] Zheng J, Sun Z, Gao Z. Empty container exchange among liner carriers. Transport Res E Logist Transport Rev 2015;83: 158-69. https://doi.org/10.1016/j.tre.2015.09.007.

[35] Zheng J, Sun Z, Zhang F. Measuring the perceived container leasing prices in liner shipping network design with empty container repositioning. Transport Res E Logist Transport Rev 2016;94:123-40. https://doi.org/10.1016/ j.tre.2016.08.001. 